ISSN 0103-9954

\title{
CRESCIMENTO E PRODUÇÃO DE POVOAMENTOS MONOCLONAIS DE Eucalyptus saligna Smith MANEJADOS COM DESBASTE, NA REGIÃO SUDESTE DO ESTADO DO RIO GRANDE DO SUL
}

\author{
GROWTH AND YIELD OF MONOCLONAL THINNED STANDS OF Eucalyptus saligna Smith, \\ IN THE SOUTHEASTERN REGION OF RIO GRANDE DO SUL STATE.
}

\author{
Luciano Weber Scheeren ${ }^{1}$ Paulo Renato Schneider ${ }^{2}$ César Augusto Guimarães Finger ${ }^{3}$ \\ RESUMO
}

Neste trabalho, foram estudados o crescimento e a produção de povoamentos monoclonais de Eucalyptus saligna Smith, manejados em alto fuste, na região sudeste do estado do Rio Grande do Sul. Para tanto foi analisado um experimento de desbaste com delineamento blocos ao acaso, instalado aos 60 meses de idade e mensurado anualmente até os 135 meses, com 5 tratamentos e três repetições. Pelo comportamento da Testemunha sem desbaste e dos tratamentos com manutenção de índices de espaçamento relativo de 16, 23, 28 e $33 \%$ verificou-se a influência no crescimento e na produção, obtendo-se os parâmetros dendrométricos. Os resultados obtidos no experimento indicam a manutenção de índices de espaçamento relativo entre $16 \%$ e $23 \%$, por ocasionarem menor perda de produção total e ganho significativo em diâmetro médio (DAP).

Palavras-chave: desbaste; crescimento; produção; Eucalyptus saligna.

\begin{abstract}
In this paper there were studied the growth and yield of monoclonal thinned stands of Eucalyptus saligna Smith, in the southeastern region of Rio Grande do Sul state. An experiment in randomized blocks was analyzed, initiated at the age of 60 months and measured annually up to 135 months, with 5 treatments and three replication. The behavior of the control treatment, without thinning, and the treatments with maintenance of relative spacing indexes of 16, 23, 28 and 33\% indicates influence in growth and yield, being obtained the dendrometric parameters. The results indicate the maintenance of indexes of relative spacing between 16 and $23 \%$, since these cause less loss in total production and significant increment in average diameter (DBH).
\end{abstract}

Key words: thinning; growth; yield; Eucalyptus saligna.

\section{INTRODUÇÃO}

O conhecimento sobre a dinâmica de crescimento dos povoamentos florestais e o desenvolvimento de planos de manejo adequados aos objetivos de produção são indispensáveis para que se possa fornecer um suprimento contínuo de madeira às indústrias. A dinâmica de crescimento da floresta pode ser compreendida pelos estudos de crescimento e produção, que analisam a relação entre quaisquer medidas de produção florestal, dentre as quais o volume é a mais usada, em relação a variáveis como idade, qualidade do sítio e densidade do povoamento.

Ao manejar um povoamento florestal, deve-se levar em consideração todos os fatores que influenciam no crescimento, de tal maneira que seja aproveitada ao máximo a capacidade produtiva do sítio. Da mesma forma, deve ser observada a potencialidade de utilização das árvores, em relação a forma e dimensões alcançadas pelo fuste. Quando a densidade do povoamento for muito baixa, pode-se não estar aproveitando todo o potencial do sítio, em termos de luz, nutrientes e água disponíveis no local. Por outro lado, se a densidade for muito elevada, estes elementos, muitas vezes, não são suficientes para garantir o bom desenvolvimento das árvores do povoamento.

1. Engenheiro Florestal, Dr, Av Cel Lucas de Oliveira, 2658 apto 403 Petrópolis, CEP: 90.460-000. Porto Alegre, RS.scheerenlw@hotmail.com

2. Engenheiro Florestal, Dr., Professor Titular do Departamento de Ciências Florestais, Centro de Ciências Rurais, Universidade Federal de Santa Maria, CEP 97105-900, Santa Maria (RS).paulors@smail.ufsm.br

3. Engenheiro Florestal, Dr., Professor Adjunto do Departamento de Ciências Florestais, Centro de Ciências Rurais, Universidade Federal de Santa Maria, CEP 97105-900, Santa Maria (RS). finger@ccr.ufsm.br

Recebido para publicação em 24/11/2003 e aceito em 21/10/2004. 
Com a execução do desbaste, o espaço vital para cada árvore é aumentado, proporcionando o desenvolvimento equilibrado da copa e do sistema radicular, de acordo com a dimensão da árvore. Entretanto, desbastes muito pesados podem levar ao aumento desproporcional do tamanho da copa e dos galhos, reduzindo a qualidade da madeira, bem como a produção volumétrica da floresta. Por outro lado, desbastes de intensidade adequada, aplicados no momento certo, permitem melhorar a qualidade da madeira, homogenizar os sortimentos e aumentar a dimensão das árvores, sem ocorrência de perdas significativas de produção.

Face ao exposto, este trabalho foi realizado com o objetivo de conhecer a influência de diferentes intensidades de desbaste sobre o crescimento em diâmetro, altura média e produção total de povoamentos monoclonais de Eucalyptus saligna Smith.

\section{REVISÃO BIBLIOGRÁFICA}

O crescimento em diâmetro é diretamente afetado pela densidade e, por conseqüência, sofre influência direta dos desbastes. Após um desbaste, as árvores de uma mesma classe diamétrica inicial atingem outras classes, num curto período de tempo (Reinstorf, 1970; Schneider, 1993).

A densidade de um povoamento é a expressão quantitativa da população de árvores por unidade de área e pode ser descrita pela área basal, volume e freqüência de forma isolada ou associada a outras variáveis para definir o espaço horizontal (Schneider,1993).

Para melhor distribuir o espaço horizontal, a prática de desbaste permite direcionar o potencial produtivo do sítio para as árvores de maior valor comercial e evitar sua dispersão em indivíduos indesejáveis ou de menor valor (Schultz, 1969).

No entanto, existem limites para esse aumento em incremento, pois aberturas excessivas, ou graus muito fortes de desbaste, podem ocasionar perdas em produção, visto que as árvores remanescentes não são capazes de repor o volume retirado no desbaste. Isto ocorre principalmente em povoamentos mais velhos (Alves, 1982).

As árvores a serem eliminadas no desbaste devem ser as mortas, dominadas ou defeituosas. Os indivíduos remanescentes são escolhidos de acordo com determinadas características previamente estabelecidas, variáveis em função do propósito a que se destina a produção. A distribuição uniforme dos indivíduos na área deve ser considerada, mesmo que algumas árvores de boas características sejam eliminadas e outras menos desejáveis continuem a compor o povoamento (Simões et al., 1981).

Os desbastes, entendidos como cortes parciais de árvores no povoamento, realizados a partir do fechamento do dossel, têm, muitas vezes, como indicador e controle a área basal. Embora esta grandeza seja largamente empregada para esse fim, se tomada isoladamente, pode não descrever o real grau de competição entre as árvores, o que se torna evidente, por exemplo, em sítios com diferentes capacidades de produção.

Assmann (1961), analisando a reação dos povoamentos florestais submetidos a desbastes, observou que as árvores remanescentes aumentavam rapidamente o incremento volumétrico, devido ao melhor aproveitamento dos fatores ambientais. Observou, ainda, que este efeito, ao qual denominou de Efeito de Aceleração do Crescimento, é dependente da época de aplicação do desbaste e do seu peso.

A resposta em "aceleração do crescimento" não é imediata, já que uma árvore pode levar até quatro anos para ampliar sua superfície folhar e radicular e, a partir daí, produzir um incremento significativo em diâmetro (Mason apud Schneider, 1993).

A observação do desenvolvimento da área basal em povoamentos desbastados e não-desbastados levou Assmann (1968) à definição dos termos: Área Basal Máxima, a qual é estabelecida em povoamentos não desbastados e representa o número de árvores de determinada dimensão que podem ser mantidas vivas e nutridas em uma condição ecológica; Área Basal Ótima, que proporciona o maior incremento volumétrico; e Área Basal Crítica, que permite alcançar 95\% do crescimento volumétrico ótimo.

Flotz et al.(1967) constataram, em estudo com Pinus sp., que remoções de 35\% e 40\% do nível máximo de área basal não influenciavam a taxa de crescimento em volume do povoamento e que remoções 
superiores a 40\% da área basal máxima resultaram num marcante declínio da produção.

Glufke(1996) encontrou como grau de estoqueamento crítico, para Pinus elliottii Engelm o valor 0,87 e verificou que desbastes de $25 \%, 50 \%$ e $75 \%$ da área basal máxima reduziram a produção na ordem de $9 \%, 20 \%$ e $54 \%$, respectivamente.

Fishwick apud Bertoloti et al.(1983) constataram que o aumento da produção volumétrica em árvores, em muitos casos, não resulta da adoção de desbastes excessivamente drásticos, pois as árvores possuem uma capacidade limitada de utilizar o espaço que lhes é oferecido no interior do povoamento.

Laar apud FAO (1981) também relatou a redução da produção em povoamentos desbastados, observando perdas de produção da ordem de $15 \%$ em volume, mas, em contrapartida, um ganho em dobro do incremento em diâmetro nos povoamentos desbastados de Eucalyptus grandis, na região de Transvaal, na África do Sul.

Os efeitos sobre a produção, o diâmetro médio e a estrutura de povoamentos de Eucalyptus camaldulensis, no Estado de Minas Gerais, através da redução da área basal, foram também constatados por Lisita et al. (1997). Os autores observaram que a produção tende a ser menor nos maiores níveis de redução de área basal e que a idade de corte é maior nos locais de maior redução. Porém, constataram que, quanto maior o nível de redução da área basal, maior a concentração da produção nas maiores classes de diâmetro.

\section{MATERIAL E MÉTODOS}

\section{Caracterização geral da área}

A empresa possui 39.554 hectares reflorestados com espécies do gênero Eucalyptus, distribuídos por 24 municípios, localizados nas regiões da Depressão Central, Serra do Sudeste e Litoral do estado do Rio Grande do Sul. A partir da década de 70, a empresa começou a investir em um grande programa de melhoramento genético, com a seleção de matrizes e estacas, sendo que atualmente possui 8.381 hectares plantados com clones e híbridos.

A área plantada com o clone 4013 de Eucalyptus saligna é de aproximadamente 1.300 hectares. As matrizes foram originadas de sementes coletadas na Austrália e levadas para Itatinga - SP, onde foram semeadas e selecionadas as melhores árvores, principalmente em relação ao crescimento e à qualidade do fuste.

Conforme a classificação de Köppen, o clima geral da região é caracterizado como $\mathrm{Cfa}$, ou seja, mesotérmico subtropical, com verões quentes e sem estação seca. A precipitação média anual é de $1.500 \mathrm{~mm}$, com máxima precipitação nos meses de julho, agosto e setembro. A temperatura média anual é de $16{ }^{0} \mathrm{C}$, com temperatura média do mês mais quente de $20{ }^{\circ} \mathrm{C}$ e do mês mais frio de $10{ }^{\circ} \mathrm{C}$. O número médio de geadas varia entre dez, na região de Encruzilhada do Sul, podendo chegar a trinta na região de Bagé (Moreno, 1961).

Os solos encontrados na região Sudeste, conforme a classificação existente, são Cambissolos e Neossolos, podendo ocorrer Gleissolos e Planossolos, característicos da região litorânea, e, também, Nitossolos e Argissolos, característicos da Depressão Central (EMBRAPA, 1999).

$\mathrm{O}$ experimento de desbaste foi instalado no horto florestal Barba Negra, em um povoamento monoclonal de Eucalyptus saligna com 5 anos de idade.

A implantação da floresta ocorreu em 1991, sendo utilizado o espaçamento 3,0 x 3,0 metros, resultando em uma densidade inicial de 1.111 árvores por hectare.

\section{Caracterização do experimento}

O delineamento experimental utilizado foi de blocos ao acaso, com 3 repetições para cada tratamento. Foram estudados cinco tratamentos, sendo mantido um índice de espaçamento relativo (S\%) fixo para cada tratamento: $\mathrm{T}=$ testemunha sem desbaste; $\mathrm{S} \%=16 ; \mathrm{S} \%=23 ; \mathrm{S} \%=28$ e $\mathrm{S} \%=33$.

Foram utilizadas unidades amostrais de $19 \mathrm{~m}$ x $30 \mathrm{~m}$, totalizando uma área útil de $570 \mathrm{~m}^{2}$. Em cada bloco, a $8^{\mathrm{a}}$ e a $11^{\mathrm{a}}$ árvores foram consideradas bordaduras internas, respectivamente, entre os blocos e as 
unidades de um mesmo bloco.

O primeiro desbaste foi realizado em junho de 1991, quando o povoamento estava com 61 meses de idade. O método de desbaste adotado foi o seletivo por baixo, sendo eliminadas as árvores dominadas, fracas, tortas ou bifurcadas, assim como outras de boas características, a fim de permitir uma distribuição uniforme das árvores remanescentes no terreno, sem deixar clareiras ou aglomerações no interior das parcelas.

O segundo desbaste foi realizado em 1998, aos 85 meses de idade, e o terceiro desbaste, em 2002, na idade de 135 meses. Foram realizadas avaliações anuais de altura e diâmetro das árvores remanescentes nas idades de 60, 73, 85, 97, 109, 121 e 135 meses (dos 5 aos 11 anos).

\section{Informações coletadas e análise do experimento}

A idade foi determinada em meses, contados a partir da data de plantio do povoamento, com base nas informações cadastrais.

Nas parcelas, foram medidos os DAPs (diâmetro à altura do peito), com precisão de décimos de centímetros, de todas as árvores úteis das unidades experimentais. Esta medida foi tomada com suta diamétrica sob a posição do DAP. As alturas de todas as árvores foram medidas com precisão de décimos de metro, usando o hipsômetro suunto. Todos os diâmetros e alturas foram medidos antes e depois dos desbastes.

O volume das árvores foi determinado pela função ajustada com os dados das árvores cubadas pelo método de Smalian, desenvolvida previamente pela empresa e expressa por:

$$
v_{c c}=b_{0}+b_{1} d+b_{2} d^{2}+b_{3} d \cdot h+b_{4} d^{2} \cdot h+b_{5} h
$$

Em que: $\mathrm{vc}_{\mathrm{cc}}=$ volume comercial com casca $\left(\mathrm{m}^{3}\right) ; \mathrm{d}=$ diâmetro à altura do peito $(\mathrm{cm}) ; \mathrm{h}=$ altura total $(\mathrm{m})$.

$\mathrm{O}$ experimento foi medido e analisado anualmente, fornecendo informações sobre o crescimento e a produção da floresta para cada um dos tratamentos de intensidade de desbaste testados. As médias dos tratamentos foram comparadas através do teste de Tukey, ao nível de $95 \%$ de confiabilidade.

\section{RESULTADOS E DISCUSSÃO}

\section{Estudo do diâmetro médio}

Na Tabela 1, é apresentada a análise da variância para a variável diâmetro médio. Observou-se que o efeito dos blocos não foi significativo (Prob. $>F=0,9598$ ), enquanto que o efeito dos tratamentos foi altamente significativo (Prob. $>\mathrm{F}=0,0001$ ).

TABELA 1: Análise da variância para diâmetro médio aos 135 meses de idade.

TABLE 1: Variance analysis for average diameter at age of 135 months.

\begin{tabular}{l|rrrr|c|c}
\hline F.V. & G. L. & S.Q. & Q.M. & F & Prob. $>$ F \\
\hline Modelo & 6 & 513,757 & 85,626 & 150,93 & 0,0001 \\
Blocos & 2 & 0,048 & 0,024 & 0,04 & 0,9588 \\
Tratamentos & 4 & 513,709 & 128,427 & 226,37 & 0,0001 \\
Resíduo & 8 & 4,539 & 0,567 & & \\
\hline Total & 14 & 518,296 & & & \\
\hline
\end{tabular}

Em que: F.V. = fonte de variação; G.L. = graus de liberdade; S.Q. = soma de quadrados; Q.M. = quadrado médio; F = valor de F calculado; Prob.> F = probabilidade de significância para o valor de F.

A Tabela 2 mostra os resultados do teste de comparação de médias, através do método de Tukey, para os tratamentos em estudo.

O teste de Tukey indicou que os diâmetros médios dos tratamentos Testemunha e $\mathrm{S} \%=16$ diferiram significativamente entre si e dos demais, não havendo diferença significativa entre os tratamentos $\mathrm{S} \%=23 \mathrm{e}$ $\mathrm{S} \%=28$ e os tratamentos $\mathrm{S} \%=28$ e $\mathrm{S} \%=33$. 
TABELA 2: Comparação das médias de diâmetro médio $(\bar{d})$ pelo teste de Tukey, aos 135 meses de idade.

TABLE 2: Means comparison for average diameter $(\bar{d})$ by the Tukey test, at age of 135 months.

\begin{tabular}{l|c|c|c}
\hline \multirow{2}{*}{ Tratamentos } & \multirow{2}{*}{ Diâmetros médios $(\mathrm{cm})$} & \multicolumn{2}{c}{ Diferenças dos diâmetros } \\
\cline { 3 - 4 } & $21,7 \mathrm{a}$ & $\mathrm{cm}$ & $\%$ \\
\hline Testemunha $(\mathrm{S} \%=8)$ & $28,2 \mathrm{~b}$ & 6,5 & - \\
$\mathrm{S} \%=16$ & $34,3 \mathrm{c}$ & 12,6 & 30,0 \\
$\mathrm{~S} \%=23$ & $36,0 \mathrm{c} \mathrm{d}$ & 14,3 & 68,1 \\
$\mathrm{~S} \%=28$ & $37,5 \mathrm{~d}$ & 15,8 & 72,8 \\
$\mathrm{~S} \%=33$ &
\end{tabular}

Médias seguidas de mesma letra não são estatisticamente diferentes, ao nível de 5\% de probabilidade de erro.

A maior diferença entre as médias ficou entre o diâmetro médio da Testemunha e $\mathrm{S} \%=33$, que apresentou diâmetro médio $72,8 \%$ superior. A menor diferença relativa ficou entre o tratamento com manutenção de $16 \%$ de espaçamento relativo e a Testemunha, com $30 \%$ ou $6,5 \mathrm{~cm}$.

Os resultados demonstraram que o intervalo entre os tratamentos foi bem dimensionado, pois a maioria dos tratamentos apresentou diferenças estatísticas. Intervalos mais próximos poderiam resultar em tratamentos estatisticamente idênticos, prejudicando a análise dos resultados.

A Figura 1 mostra a dispersão dos diâmetros observados para cada tratamento e a respectiva média. Os resultados são apresentados para as idades de 61, 85 e 135 meses, correspondentes às idades em que foram realizadas as intervenções de desbaste.
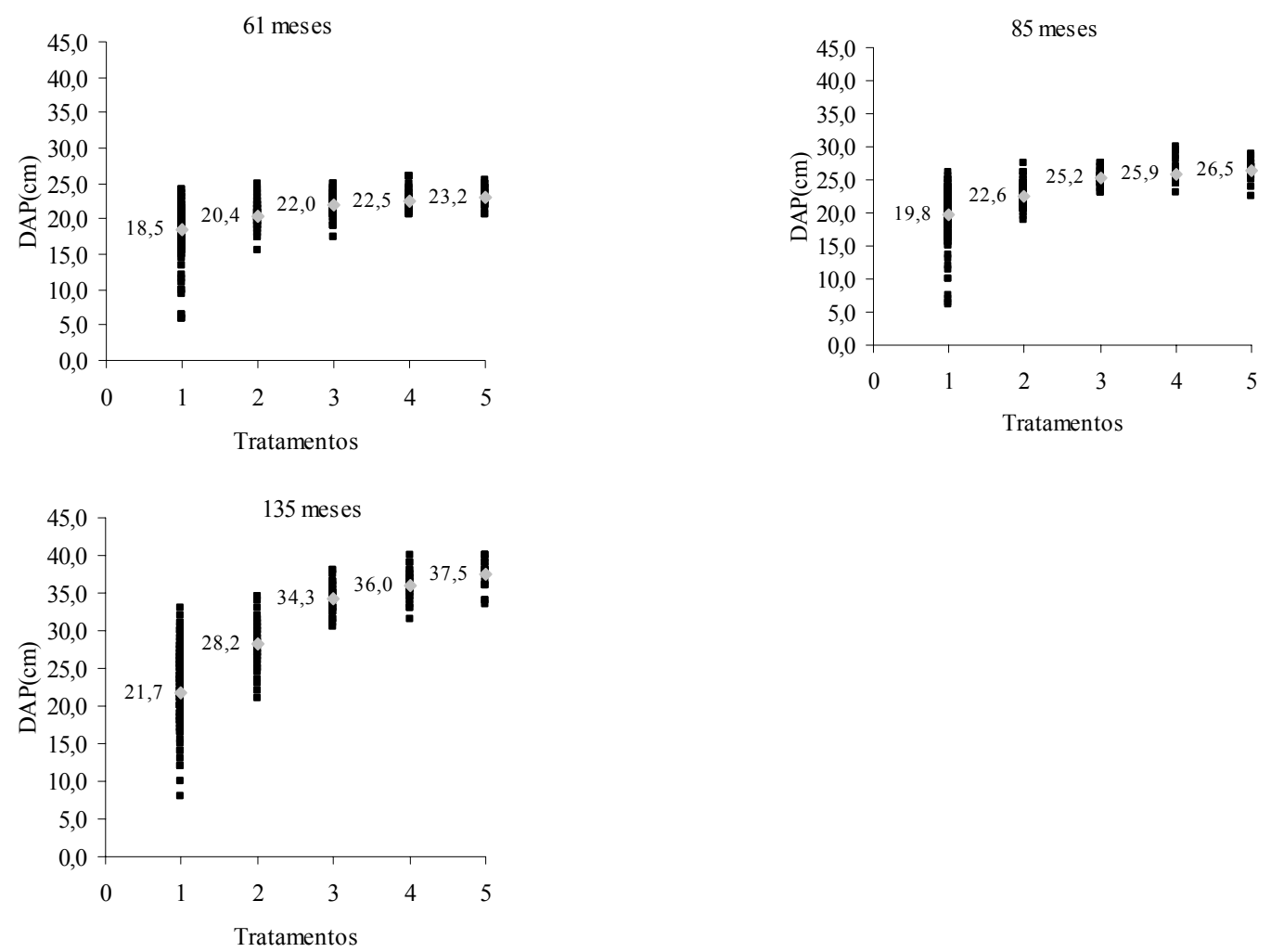

FIGURA 1: Dispersão de diâmetros (DAP) e diâmetro médio $(\bar{d})$ observados.

FIGURE 1: Dispersion of diameter (DBH) and medium diameter $(\bar{d})$ observed.

Os diâmetros apresentados foram tomados imediatamente após a realização do primeiro desbaste, aos 61 meses de idade, e antes do segundo e do terceiro desbastes, aos 85 e 135 meses respectivamente, 
sendo medidas todas as árvores remanescentes de cada tratamento.

Verificou-se a ocorrência de maior dispersão dos diâmetros na Testemunha. Essa dispersão apresentou tendência a aumentar com o passar do tempo, uma vez que as árvores das menores classes de diâmetro ficaram estagnadas, enquanto que as árvores das maiores classes de diâmetro continuaram incrementando em diâmetro, elevando a amplitude da dispersão nas classes de diâmetro acima da média do tratamento.

Nos demais tratamentos, a dispersão dos diâmetros foi decrescente, conforme o aumento do peso de desbaste. Essa redução na dispersão dos diâmetros ocorreu nas classes de diâmetro inferiores à média, sendo devida ao tipo de desbaste utilizado (por baixo).

Em 1996, quando o povoamento estava com idade de 60 meses, as médias dos tratamentos com desbaste tiveram um aumento significativo, como resultado da intervenção. Esse aumento foi crescente de acordo com a elevação do peso de desbaste, sendo da ordem de $10,3 \%$ para o tratamento $\mathrm{S} \%=16$ e de $25,4 \%$ para o tratamento $\mathrm{S} \%=33$, relativo ao tratamento sem desbaste. Em 1998, quando o povoamento estava com idade de 85 meses, as médias dos tratamentos $\mathrm{S} \%=16$ e $\mathrm{S} \%=33$ apresentavam diferenças relativas à Testemunha de $14,1 \%$ e $33,8 \%$, respectivamente. A evolução do diâmetro médio na Testemunha, durante o mesmo período (1996-1998), chegou a um aumento de 7,0\%, sendo de $10,8 \%$ para o tratamento $\mathrm{S} \%=16$ e de $14,2 \%$ para o tratamento $\mathrm{S} \%=23$. Isso resultou em aumento ou aceleração de crescimento nos tratamentos desbastados da ordem de $3,8 \%$ no tratamento $\mathrm{S} \%=16(10,8 \%-7,0 \%)$ e de $7,2 \%$ no tratamento $\mathrm{S} \%=33(14,2 \%-7,0 \%)$.

No período entre o segundo e o terceiro desbastes (1998-2002), o crescimento do diâmetro médio na testemunha atingiu $9,6 \%$. No tratamento $\mathrm{S} \%=16$, esse índice chegou a $24,8 \%$ e, no tratamento $\mathrm{S} \%=33$, resultou em 41,5\%. Dessa forma, durante esse período, obteve-se uma aceleração no crescimento em diâmetro de $15,2 \%$ para o tratamento $\mathrm{S} \%=16(24,8 \%-9,6 \%)$ e de $31,9 \%$ para o tratamento $\mathrm{S} \%=33(41,5 \%$ $9,6 \%$ ).

Isto está de acordo com os objetivos da execução de desbastes, ou seja, após uma intervenção, ocorre o efeito de aceleração no crescimento em diâmetro no povoamento remanescente. Esses resultados demonstraram que o material genético em estudo apresentou uma resposta muito positiva às intervenções de desbaste, resultando altas taxas de incremento em diâmetro médio.

A Figura 2 mostra a evolução do diâmetro médio nas idades em que foram realizados inventários no experimento.

Percebeu-se, em todos os tratamentos desbastados, uma curva crescente, não se verificando tendência assintótica até o final do período de observação. Isso não ocorreu com a Testemunha, que mostrou uma tendência assintótica ou de estabilização da curva de crescimento em diâmetro médio. O elevado nível de competição entre as árvores nesse tratamento impediu um melhor desempenho no crescimento em diâmetro, que só voltou a ocorrer quando se verificou a diminuição do número de árvores como efeito da mortalidade natural.

Entre o período de 109 a 121 meses, verificou-se uma mortalidade natural de 20 árvores por hectare nas unidades amostrais da testemunha. O efeito dessa mortalidade natural pode ser observado na Figura 2, revelando um comportamento atípico da curva de crescimento em diâmetro médio nesse período. 


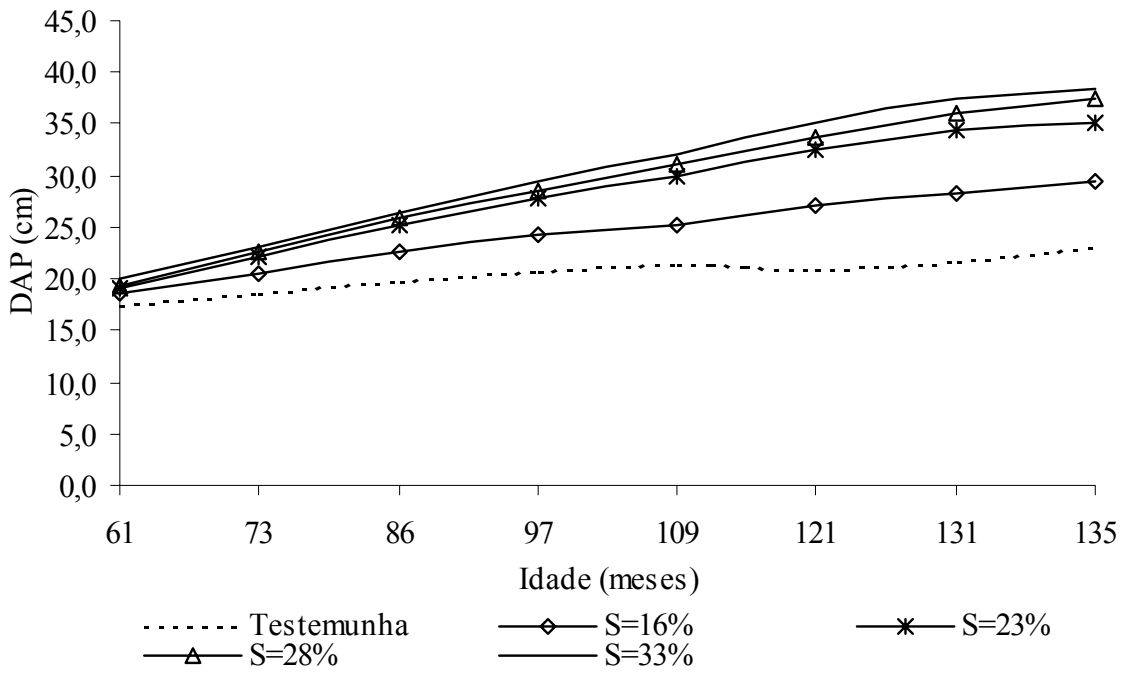

FIGURA 2: Evolução do diâmetro médio $(\bar{d})$ por idade.

FIGURE 2: Evolution of average diameter $(\bar{d})$ by age.

\section{Estudo da altura média $\left(h_{m}\right)$}

Na Tabela 3, é apresentada a análise da variância para a variável altura média. Observou-se que o efeito dos blocos foi não-significativo (Prob. $>\mathrm{F}=0,1563$ ), enquanto o efeito dos tratamentos foi altamente significativo (Prob. $>\mathrm{F}=0,006$ ).

TABELA 3: Análise da variância para altura média aos 135 meses de idade.

TABLE 3: Variance analysis for the average height at age of 135 months.

\begin{tabular}{l|c|r|r|r|c}
\hline F.V. & G. L. & S.Q. & Q.M. & F & Prob.>F \\
\hline Modelo & 6 & 69,366 & 11,561 & 12,06 & 0,0012 \\
Blocos & 2 & 4,529 & 2,264 & 2,36 & 0,1563 \\
Tratamentos & 4 & 64,837 & 16,209 & 16,91 & 0,0006 \\
Resíduo & 8 & 7,671 & 0,959 & & \\
\hline Total & 14 & 77,037 & & &
\end{tabular}

Em que: F.V. = fonte de variação; G.L. = graus de liberdade; S.Q. = soma de quadrados; Q.M. = quadrado médio; F = valor de F calculado; Prob.> F = probabilidade de significância para o valor de F.

A Tabela 4 apresenta o teste de comparação de médias para a altura média, utilizando o teste de Tukey.

TABELA 4: Comparação das médias de altura média $\left(\mathrm{h}_{\mathrm{m}}\right)$ pelo teste de Tukey, aos 135 meses de idade.

TABLE 4: Means comparison for average height $\left(\mathrm{h}_{\mathrm{m}}\right)$ by the Tukey test, at age of 135 months.

\begin{tabular}{l|c|c|c}
\hline \multirow{2}{*}{ Tratamentos } & \multirow{2}{*}{$\mathrm{h}_{\mathrm{m}}(\mathrm{m})$} & $(\mathrm{m})$ & Diferenças de $\mathrm{h}_{\mathrm{m}}$ \\
\cline { 3 - 4 } & $31,9 \mathrm{a}$ & - & - \\
\hline Testemunha & $36,8 \mathrm{~b}$ & 5,0 & 15,5 \\
$\mathrm{~S} \%=16$ & $36,1 \mathrm{~b}$ & 4,2 & 13,3 \\
$\mathrm{~S} \%=23$ & $37,9 \mathrm{~b}$ & 6,0 & 18,7 \\
$\mathrm{~S} \%=28$ & $36,6 \mathrm{~b}$ & 4,7 & 14,7 \\
$\mathrm{~S} \%=33$ &
\end{tabular}

Médias seguidas de mesma letra não são estatisticamente diferentes, ao nível de 5\% de probabilidade de erro.

A média mostrou-se estatisticamente diferente apenas para a testemunha, que diferiu dos demais tratamentos. Esse resultado demonstrou que o efeito da competição no crescimento em altura média foi eliminado com a utilização de desbastes, mesmo no caso de desbastes leves $(\mathrm{S} \%=16)$. 
Nos tratamentos desbastados, a altura média não apresentou tendência nítida com respeito ao peso de desbaste, mantendo um acréscimo no crescimento em altura de $13,3 \%(\mathrm{~S} \%=23)$ a $18,7 \%(\mathrm{~S} \%=28)$ em relação à testemunha.

A Figura 3 mostra o desenvolvimento em altura média para os tratamentos estudados durante todo o período de observação, na qual se pode notar uma oscilação na taxa de crescimento em altura média. Essa oscilação, até a idade de 109 meses, foi atribuída a fatores ambientais, uma vez que a testemunha apresentou a mesma tendência dos tratamentos com desbaste.

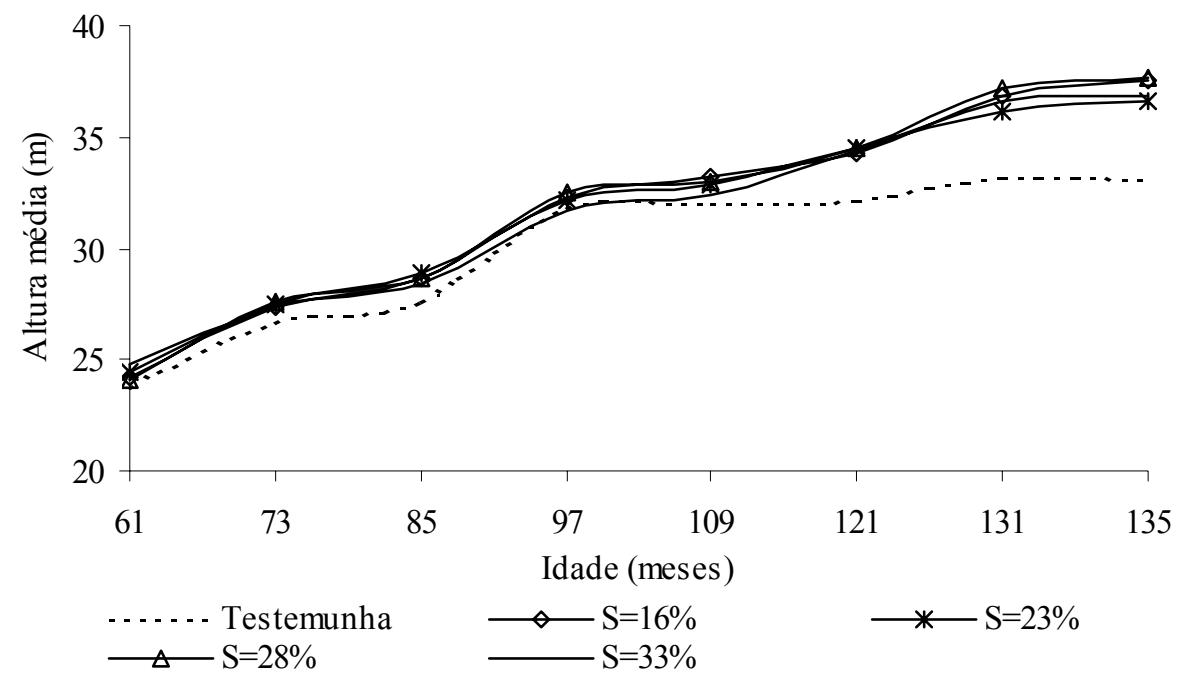

FIGURA 3: Crescimento em altura média $\left(\mathrm{h}_{\mathrm{m}}\right)$ por idade

FIGURE 3: Growth in average height $\left(\mathrm{h}_{\mathrm{m}}\right)$ by age.

Entretanto, a partir dos 109 meses, notou-se que a competição comessou a afetar o crescimento em altura média na testemunha, chegando, aos 135 meses de idade, a alturas significativamente diferentes das encontradas nos tratamentos com desbastes.

\section{Estudo da produção total $\left(\mathbf{P}_{t}\right)$}

A análise da variância da produção total, apresentada na Tabela 5, dada pelo somatório do volume total das árvores remanescentes com o somatório dos volumes desbastados, aos 135 meses de idade, não mostrou diferença significativa entre os blocos (Prob. $>F=0,5289$ ). Os tratamentos, entretanto, foram altamente significativos (Prob. $>\mathrm{F}=0,0001$ ), indicando que as diferenças do volume observado são devidas aos diferentes pesos de desbastes aplicados.

TABELA 5: Análise da Variância para volume total com casca aos 135 meses de idade.

TABLE 5: Variance analysis for the total volume with bark at age of 135 months.

\begin{tabular}{l|c|r|r|r|l}
\hline F.V. & G. L. & \multicolumn{1}{c}{ S.Q. } & Q.M. & F & Prob. $>$ F \\
\hline Modelo & 6 & 192641,8 & 32106,9 & 35,4 & 0,0001 \\
Blocos & 2 & 1254,0 & 627,0 & 0,7 & 0,5289 \\
Tratamentos & 4 & 191387,8 & 47846,9 & 52,7 & 0,0001 \\
Resíduo & 8 & 7265,0 & 908,1 & & \\
Total & 14 & 199906,9 & & & \\
\hline
\end{tabular}

Em que: F.V. = fonte de variação; G.L. = graus de liberdade; S.Q. = soma de quadrados; Q.M. = quadrado médio; F = valor de F calculado; Prob.> F = probabilidade de significância para o valor de F.

A Tabela 6 mostra o teste de comparação de médias de Tukey para o volume total com casca e as diferenças absolutas e relativas dos tratamentos com a testemunha. A produção da testemunha apresentou diferença significativa com os demais tratamentos, assim como o tratamento com manutenção de $16 \%$ de espaçamento relativo. 
TABELA 6: Comparação das médias de volume total por hectare (VTc/c) aos 135 meses de idade. TABLE 6: Means comparison for total volume (VTc/c) at age of 135 months.

\begin{tabular}{l|c|c|c}
\hline \multirow{2}{*}{ Tratamentos } & \multirow{2}{*}{$\begin{array}{c}\text { VTc/c } \\
\left(\mathrm{m}^{3} / \mathrm{ha}\right)\end{array}$} & \multicolumn{2}{c}{ Diferenças de VTc/c } \\
\cline { 3 - 4 } & $814,4 \mathrm{a}$ & - & $\%$ \\
\hline Testemunha & $710,3 \mathrm{~b}$ & 104,2 & - \\
S\% $=16$ & $589,7 \quad \mathrm{c}$ & 224,7 & $-12,8$ \\
$\mathrm{~S} \%=23$ & $547,8 \mathrm{~cd}$ & 266,6 & $-27,6$ \\
$\mathrm{~S} \%=28$ & $507,3 \quad \mathrm{~d}$ & 307,1 & $-32,7$ \\
S\% $=33$ & &
\end{tabular}

Médias seguidas de mesma letra não são estatisticamente diferentes, ao nível de $5 \%$ de probabilidade de erro.

Os tratamentos com manutenção de $23 \%$ e $28 \%$ de espaçamento relativo não diferiram significativamente entre si, bem como o tratamento com $28 \%$ de espaçamento relativo do tratamento com manutenção de $33 \%$.

$\mathrm{Na}$ Figura 4, são apresentadas as produções totais para cada tratamento e a respectiva perda de produção volumétrica, comparativamente à produção da testemunha sem desbaste.

As perdas de produção, relativas à produção total da testemunha, mostraram valores elevados, partindo de $12,8 \%$, no tratamento com desbastes mais leves, $(\mathrm{S} \%=16)$ e chegando a $37,7 \%$, no tratamento com desbastes mais pesados $(\mathrm{S} \%=33)$.

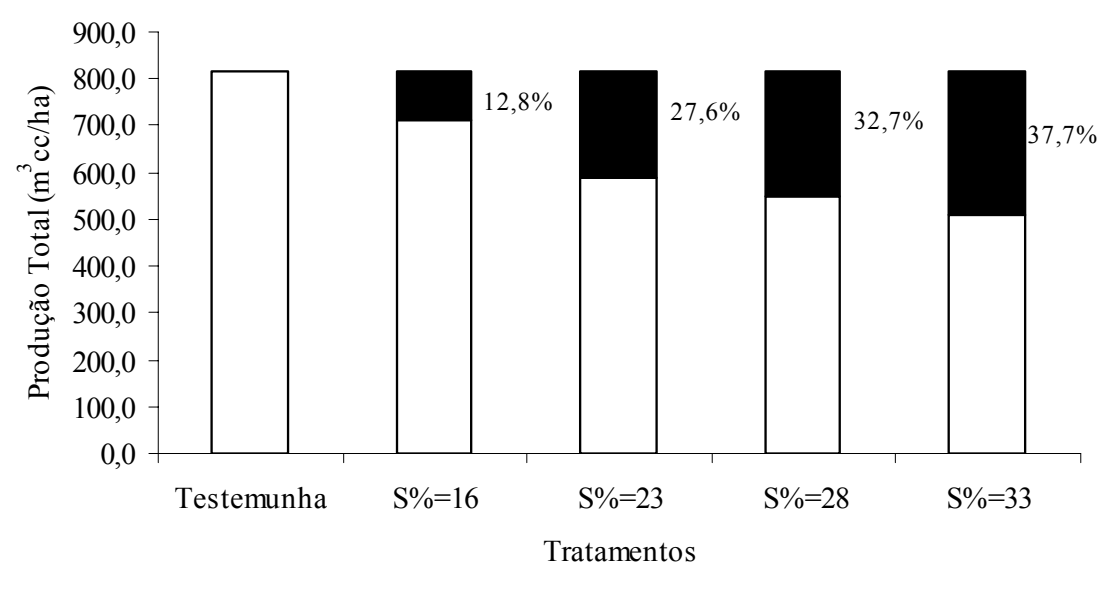

$\square$ Produção Total

- Perda de Produção (\%)

FIGURA 4: Perdas de produção total $\left(\mathrm{m}^{3} \mathrm{cc} / \mathrm{ha}\right)$ dos tratamentos em relação à testemunha.

FIGURE 4: Total production loss $\left(\mathrm{m}^{3} \mathrm{cc} / \mathrm{ha}\right)$ on thinned treatments in relation with the control.

Em contrapartida às elevadas perdas de produção volumétrica, cabe ressaltar o ganho em diâmetro médio obtido nos tratamentos desbastados. Este foi $30 \%$ superior à testemunha no tratamento com manutenção de $16 \%$ de índice de espaçamento relativo e de $72,8 \%$ no tratamento com manutenção de $33 \%$ de espaçamento relativo (Figura 2). Esses valores foram elevados, ratificando os resultados encontrados em trabalhos semelhantes, como os realizados por Van Laar apud FAO (1981), Schneider et al. (1998) e Lisita et al. (1997).

Van Laar apud FAO (1981) relatou sobre a redução da produção em povoamentos desbastados, cujas perdas de produção foram da ordem de $15 \%$ em volume, mas, em contrapartida, com ganho em dobro do incremento em diâmetro nos povoamentos desbastados de Eucalyptus grandis, na região de Transvaal, na África do Sul.

Em trabalho sobre os efeitos dos desbastes na produção, no diâmetro médio e na estrutura de povoamentos de Eucalyptus camaldulensis, no estado de Minas Gerais, Lisita et al. (1997) também constataram que a produção tendia a ser menor quando os níveis de redução de área basal eram mais elevados. Porém, à medida que se aumentava o nível de redução da área basal, tornava-se mais intensa a 
concentração da produção nas maiores classes de diâmetro .

Schneider et al. (1998), em estudo com Eucalyptus grandis Hill ex Maiden, aos 189 meses de idade, em que os desbastes foram controlados pela área basal, constataram que, no tratamento com menor peso de desbastes, com manutenção de $60 \%$ da área basal da testemunha, ocorreu a menor perda de produção, com cerca de $15,4 \%$. Já no tratamento mais pesado, com manutenção de $40 \%$ da área basal da testemunha, a perda de produção chegou a $29,2 \%$.

Neste sentido, Daniel et al. (1982) consideraram que, entre os efeitos esperados dos desbastes, estava a redução do volume total produzido. O manejador pouco pode fazer para aumentar o volume total, sendo questionável a possibilidade de se elevar a produção volumétrica sem introduzir um genótipo superior ou sem modificar o ambiente (sítio) através da fertilização ou irrigação.

Fishwick (1975) também comprovou que o desbaste influenciava negativamente a produção total em volume. Destacou, ainda, que a não-realização de um programa de desbaste correto pode causar uma redução séria nas dimensões do produto final. Os aumentos em produção volumétrica de madeira de alta qualidade, por árvore, em muitos casos, não foram resultantes da adoção de desbastes excessivamente drásticos, pois as árvores possuíam uma capacidade limitada de utilizar todo o espaço que lhes era oferecido no interior do povoamento.

Na Tabela 7, são apresentadas as densidades de cada tratamento, suas produções volumétricas totais e a produção média por indivíduo, anteriormente à realização do terceiro desbaste, aos 131 meses de idade.

TABELA 7: Comparação do volume individual médio ( $\left.\mathrm{V}_{\text {ind. }}\right)$ aos 131 meses de idade.

TABLE 7: Comparison of average individual volume $\left(V_{\text {ind }}\right)$ at age of 135 months.

\begin{tabular}{|c|c|c|c|c|c|}
\hline \multirow{2}{*}{ Tratamentos } & \multirow{2}{*}{$\begin{array}{l}\mathrm{N} \\
\text { (ha) }\end{array}$} & \multirow{2}{*}{$\begin{array}{l}\mathrm{VTc} / \mathrm{c} \\
\left(\mathrm{m}^{3} / \mathrm{ha}\right)\end{array}$} & \multirow{2}{*}{$\begin{array}{c}\mathrm{Vc} / \mathrm{c}_{\text {ind }} \\
\left(\mathrm{m}^{3} / \text { árv. }\right)\end{array}$} & \multicolumn{2}{|c|}{ Diferenças de $\mathrm{Vc} / \mathrm{c}_{\text {ind. }}$} \\
\hline & & & & $\mathrm{m}^{3} / \mathrm{ha}$ & $\%$ \\
\hline Testemunha $(\mathrm{S} \%=8)$ & 1.240 & 788,6 & 0,6359 & 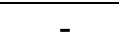 & - \\
\hline $\mathrm{S} \%=16$ & 526 & 541,0 & 1,0285 & 0,3925 & 61,7 \\
\hline $\mathrm{S} \%=23$ & 246 & 351,5 & 1,4291 & 0,7931 & 124,7 \\
\hline $\mathrm{S} \%=28$ & 175 & 289,5 & 1,6543 & 1,0184 & 160,1 \\
\hline $\mathrm{S} \%=33$ & 123 & 209,8 & 1,7054 & 1,0695 & 168,2 \\
\hline
\end{tabular}

Em que: $\mathrm{N}=$ número de árvores por hectare; $\mathrm{VTc} / \mathrm{c}=$ volume total com casca, $\mathrm{em} \mathrm{m}^{3} / \mathrm{ha} ; \mathrm{Vc} / \mathrm{c}_{\text {ind }}=$ volume médio com

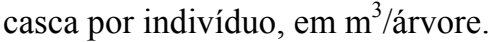

Observou-se que o volume individual dos tratamentos com desbaste, relativamente ao volume individual da testemunha, aumentou consideravelmente nos tratamentos com maior peso de desbaste, atingindo um aumento de até $168 \%$ no tratamento com desbastes mais pesados ( $\mathrm{S} \%=33$ ). Quando os tratamentos desbastados, a diferença máxima ocorreu entre o tratamento com desbastes mais leves $(\mathrm{S} \%=16)$ e o com desbastes mais pesados $(\mathrm{S} \%=33)$, chegando-se a uma diferença de $66 \%$ em volume individual.

A Figura 5 mostra a produção total em volume comercial e o respectivo diâmetro médio para cada tratamento, aos 135 meses de idade. Fica evidente que o manejo de povoamentos com desbastes sofrem, por um lado, um acréscimo considerável de diâmetro médio, e, por outro, uma drástica redução da produção total.

Dessa forma, o ponto ótimo para dimensionamento de produto final é dado pelo mercado madeireiro, que o remunera com base no diâmetro mínimo das toras requerido para a atividade industrial em questão (serraria ou laminação).

Com base nessas informações, o manejador pode dimensionar o seu sistema de desbaste, buscando atingir a maior produção possível. O resultado obtido será dado pelo equilíbrio entre o diâmetro médio desejado e as respectivas perdas de produção associadas. 


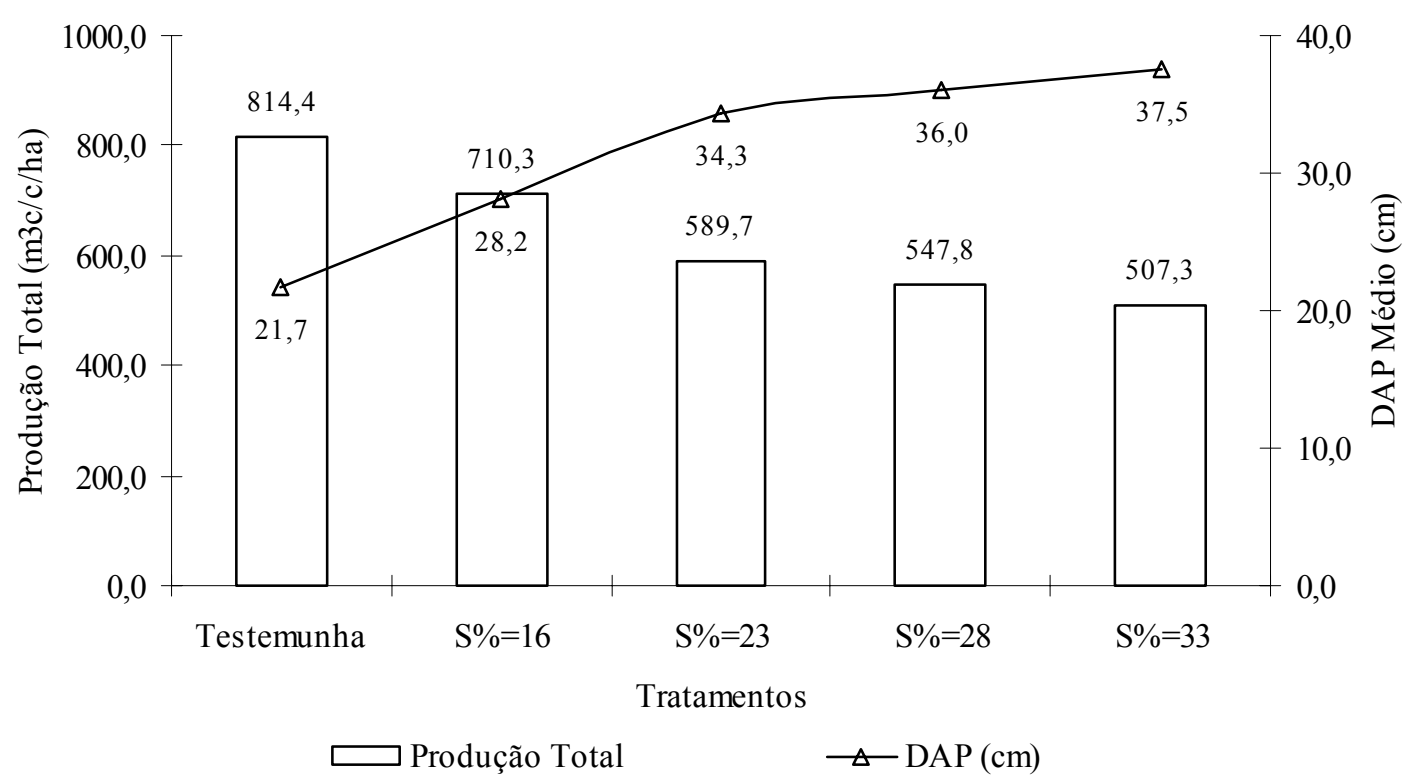

FIGURA 5: Produção total $\left(\mathrm{m}^{3} \mathrm{c} / \mathrm{d} / \mathrm{ha}\right)$ e respectivo diâmetro médio $(\mathrm{cm})$ por tratamento aos 135 meses de idade.

FIGURE 5: Total production $\left(\mathrm{m}_{\mathrm{c} / \mathrm{d}}^{3}\right.$ ha) and respective average diameter $(\mathrm{cm})$ by treatment at age of 135 months.

\section{CONCLUSÕES}

Os resultados obtidos nesse estudo, desenvolvido para o clone 4013 de Eucalyptus saligna Smith, permitem concluir que:

Os tratamentos com desbastes apresentaram ganho significativo no diâmetro médio em relação à testemunha sem desbaste, sendo esse ganho de $30 \%$ para o tratamento com desbastes mais leves $(\mathrm{S} \%=16)$, chegando até $72,8 \%$ para o tratamento com desbastes mais pesados $(\mathrm{S} \%=33)$;

A testemunha apresentou altura média significativamente menor que todos os tratamentos desbastados, sendo que a perda significativa de incremento em altura iniciou a partir dos 109 meses de idade. Os distintos pesos de desbaste não afetaram significativamente o crescimento em altura média, uma vez que não houve diferença significativa quanto a essa variável entre os tratamentos desbastados;

A produção total da testemunha e do tratamento $\mathrm{S} \%=16$ apresentaram diferença significativa entre si e dos demais tratamentos. A perda de produção em relação à testemunha foi de $12,8 \%$ para desbastes mais leves $(\mathrm{S} \%=16)$, chegando a $37,7 \%$ para desbastes mais pesados $(\mathrm{S} \%=33)$.

\section{REFERÊNCIAS BIBLIOGRÁFICAS}

ALVES, M. A. A. Técnica de produção florestal: fundamentos, tipificação e métodos. Lisboa: Instituto Nacional de Investigação Científica, 1982.331p.

ASSMANN, E. Waldertragskunde. München: BLV Verlagsgesselschaft, 1961. 425p.

ASSMANN, E. Zur Theorie der Grundflächenhaltung. Fw. Gbl. v.78, n.32, p.321-330, 1968.

BERTOLOTI, G; SIMÕES, J. W.; NICOLIELO, N.; GARNICA, J. B. Efeitos de diferentes métodos e intensidades de desbaste na produtividade de Pinus caribaea var. hondurensis Barr. et Golf. Rev. IPEF, Piracicaba, v.24, p.47-54, 1983.

DANIEL, P. W.; HELMS, U. E.; BAKER, F. S. Princípios de silvicultura. México: McGraw Hill, 1982. 492 p.

EMBRAPA. Sistema brasileiro de classificação de solos. Brasília: Embrapa, 1999. 412p. 
FAO. Food and Agriculture Organization of United Nation. Eucalyptus for planting. Italy: FAO, 1981. 677p.

FLOTZ, B. W.; JOHNSTON, W. F. Cross basal area growth of northern White ceder is independent of stand density over a wide range. 1967. (U. S. Forest Service Research. Note NC-61)

GLUFKE, C. Crescimento de Pinus elliottii Engelm em povoamento desbastado. 1996. 73p. Dissertação ( Mestrado em Engenharia Florestal)- Universidade Federal de Santa Maria, Santa Maria, 1996.

LISITA, A.; LEITE, H. G.; CAMPOS, J. C .C.; REGAZZI, A. J.; LELLIS, V. G. dos S. Efeitos de reespaçamentos na produção, no diâmetro médio e na estrutura de povoamentos de Eucalyptus camaldulensis. Rev. Árvore, v 21, n. 4 , p. 473-482, 1997.

MOREnO, J. A. Clima do Rio Grande do Sul. Porto Alegre: Secretaria da Agricultura - Diretoria de Terras e Colonização, 1961. 42p.

REINSTORF, L. O. The influence of stand density on growth of Pinus elliottii. Stellenbosch, 1970.62 p. Dissertação (Mestrado) - University of Stellenbosch., Stellenbosch, 1970.

SCHNEIDER, P. R. Introdução ao manejo florestal. Santa Maria: UFSM, 1993. 348p.

SCHNEIDER, P. R.; FINGER, C. A. G.; HOPE, J. M.; DRESCHER, R.; SCHEEREN, L. W.; MAINARDI, G.; FLEIG, F. D. Produção de Eucalyptus grandis Hill ex Maiden em diferentes intensidades de desbaste. Revista Ciência Florestal, Santa Maria, v. 8 , n. 1, p. 129-140, 1998

SCHULTZ, J. P. Curso de Silvicultura I. Merida: Universidade de Los Andes, Centro de Estudios de Posgrado, 1969. 29 p.

SIMÕES, J. W. et al. Formação, manejo e exploração de florestas com espécies de rápido crescimento. Brasília: IBDF, 1981. 131p. 